\title{
Multi-omics approach to study the growth efficiency and amino acid metabolism in Lactococcus lactis at various specific growth rates
}

Petri-Jaan Lahtvee ${ }^{1,2}$, Kaarel Adamberg ${ }^{2,3}$, Liisa Arike ${ }^{2,3}$, Ranno Nahku $^{1,2}$, Kadri Aller $^{1,2}$, Raivo Vilu ${ }^{1,2^{*}}$

\begin{abstract}
Background: Lactococcus lactis is recognised as a safe (GRAS) microorganism and has hence gained interest in numerous biotechnological approaches. As it is fastidious for several amino acids, optimization of processes which involve this organism requires a thorough understanding of its metabolic regulations during multisubstrate growth.

Results: Using glucose limited continuous cultivations, specific growth rate dependent metabolism of L. lactis including utilization of amino acids was studied based on extracellular metabolome, global transcriptome and proteome analysis. A new growth medium was designed with reduced amino acid concentrations to increase precision of measurements of consumption of amino acids. Consumption patterns were calculated for all 20 amino acids and measured carbon balance showed good fit of the data at all growth rates studied. It was observed that metabolism of L. lactis became more efficient with rising specific growth rate in the range $0.10-0.60 \mathrm{~h}^{-1}$, indicated by $30 \%$ increase in biomass yield based on glucose consumption, $50 \%$ increase in efficiency of nitrogen use for biomass synthesis, and $40 \%$ reduction in energy spilling. The latter was realized by decrease in the overall product formation and higher efficiency of incorporation of amino acids into biomass. L. lactis global transcriptome and proteome profiles showed good correlation supporting the general idea of transcription level control of bacterial metabolism, but the data indicated that substrate transport systems together with lower part of glycolysis in $L$. lactis were presumably under allosteric control.

Conclusions: The current study demonstrates advantages of the usage of strictly controlled continuous cultivation methods combined with multi-omics approach for quantitative understanding of amino acid and energy metabolism of $L$. lactis which is a valuable new knowledge for development of balanced growth media, gene manipulations for desired product formation etc. Moreover, collected dataset is an excellent input for developing metabolic models.
\end{abstract}

\section{Background}

Lactococcus (L.) lactis is the most intensively studied lactic acid bacterium and it has a great industrial importance. In addition to its wide usage in the dairy industry, L. lactis subsp. lactis IL1403 was the first lactic acid bacterium whose genome was sequenced [1], and it is extensively used for production of different metabolic products and recombinant proteins [reviews in [2-4]]. As this bacterium is generally recognised as safe (GRAS), there has been increasing interest in its use as

\footnotetext{
* Correspondence: raivo@kbfi.ee

'Tallinn University of Technology, Department of Chemistry, Akadeemia tee 15, 12618 Tallinn, Estonia

Full list of author information is available at the end of the article
}

a live vector for mucosal delivery of therapeutic proteins, including nasal and gastrointestinal vaccines $[5,6]$. However, there exists a remarkable lack of knowledge about the peculiarities of $L$. lactis metabolic regulation, especially regarding amino acid metabolism. There are several defined media designed for L. lactis [7-9], however, these are unbalanced and concentrations of individual amino acids are quite high, making their consumption measurements inaccurate as utilization by the cells is small compared to the total content. Lack of reliable information on consumption patterns and regulation of amino acid metabolism hinders design of cheaper balanced complex media and optimization of bioprocesses.

\section{Biomed Central}


Systems biology approaches where 'omics' methods are combined with advanced cultivation methods, computational and mathematical models form a solid platform for elucidating quantitative peculiarities of metabolism and its regulation in microorganisms. Transcriptome and proteome expression in L. lactis have been measured and compared several times in various phases of batch cultivations [10,11]. A multi-omics study where L. lactis was cultivated at steady state conditions was carried out by Dressaire et al. [12,13]. They characterized $L$. lactis at the transcriptome level in isoleucine limited chemostat cultures, calculated translation efficiencies based on proteome and transcriptome levels, and showed that energy costs associated with protein turnover in cells are bigger at low growth rates in comparison with higher ones.

To provide more comprehensive knowledge about amino acid metabolism in L. lactis we developed a new medium, which allowed studying quantitative patterns of amino acid consumption. To further link amino acid metabolism with the overall physiological state of cells, growth rate dependent trancriptomes, proteomes and extracellular metabolomes were measured and studied together with carbon, nitrogen and ATP, redox balance analyses. L. lactis was cultivated in accelerostat (A-stat) continuous cultures as this method allows acquisition of vast amount of data on quasi steady state growing cells and precise determination of growth characteristics, especially investigation of dependences of growth characteristics on residual concentrations of growth limiting substrate (e.g. glucose) which determines the specific growth rate of cells $(\mu)$.

\section{Results}

\section{L. lactis growth characteristics}

L. lactis was cultivated in A-stat culture where after stabilisation in chemostat at dilution rate $0.10 \mathrm{~h}^{-1}$, specific growth rate $(\mu)$ was smoothly increased until the maximal $\mu\left(\mu_{\max }\right)$ was reached at $0.59 \pm 0.02 \mathrm{~h}^{-1}$ (average value of five independent experiments \pm standard deviation; Figure 1). To obtain higher precision in the determination of amino acid consumption patterns, concentrations of most amino acids in the growth medium were reduced ca 3 times compared to the chemically defined medium (CDM) [14], exceptions being arginine and glutamine, whose concentrations were increased in the medium to avoid amino group shortage during the growth (see Methods). The residual glucose concentration remained below detection limit $(<0.1 \mathrm{mM})$ between $\mu 0.10 \mathrm{~h}^{-1}$ and $0.59 \pm 0.02 \mathrm{~h}^{-1}$ in all five independent experiments. It is important to note that constant protein content ( $45 \pm 2 \%$ of cell dry weight) and constant amino acid composition of the protein fraction was observed in the full range of $\mu$ from 0.10 to $0.55 \mathrm{~h}^{-1}$

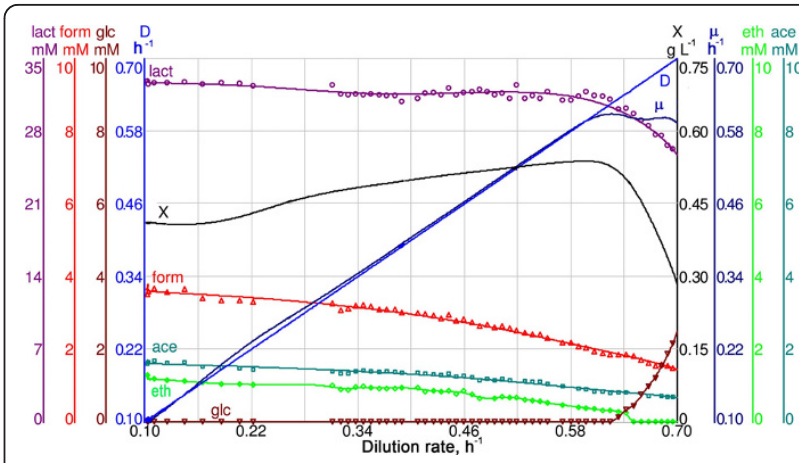

Figure 1 Typical A-stat cultivation, where dilution rate dependent metabolism of $L$. lactis is illustrated. D - dilution rate $\left(h^{-1}\right) ; X$ - biomass concentration (g (dry cellular weight) $\left.L^{-1}\right) ; \mu$ specific growth rate $\left(\mathrm{h}^{-1}\right)$; lact, form, glc, eth, ace - lactate, formate, glucose, ethanol, acetate concentration in bioreactor, respectively $(\mathrm{mM})$. D, $\mu$ and $X$ are monitored constantly; metabolite concentrations are measured with a frequency of approximately $0.01 \mathrm{~h}^{-1}$

(Additional file 1, Table S1). RNA content increased from $6.5 \pm 1.0 \%$ to $9.5 \pm 1.5 \%$ in cell dry weight in between the latter $\mu$ values. The biomass yield per consumed carbon $\left(\mathrm{Y}_{\mathrm{XC}}\right)$ increased from $0.13 \pm 0.00$ to $0.17 \pm 0.01 \mathrm{C}-\mathrm{mol}_{\text {biomass }} \mathrm{C}-\mathrm{mol}_{\text {carbon }}{ }^{-1}$ when $\mu$ was raised from $0.20 \pm 0.02 \mathrm{~h}^{-1}$ to $0.52 \pm 0.04 \mathrm{~h}^{-1}$ (Additional file 2, Table S1). It was realized by decrease of by-product formation per biomass from 89.6 to 62.3 mmol gdw ${ }^{-1}$ (sum of $Y_{\text {lact }}, Y_{\text {ace }}$ and $Y_{\text {eth }}$, Additional file 2, Table S1). Corresponding yield of these by-products (lactate, acetate, ethanol) per consumed glucose decreased from 2.05 to $1.88 \mathrm{~mol}_{\text {products }} \mathrm{mol}_{\mathrm{glc}}{ }^{-1}$, with lactate yield per consumed glucose $\mathrm{Y}_{\mathrm{lg}}=1.83 \pm 0.03$ mol lact mol glc $^{-1}$ remaining constant. As by-product formation exceeded maximal possible yield $\left(2 \mathrm{~mol} \mathrm{~mol}^{-1}\right)$ per consumed glucose at growth rates below $0.4 \mathrm{~h}^{-1}$ (Additional file 1, Table S2) it indicated that part of the amino acids should have been catabolised to pyruvate and eventually to by-products. The overall consumption of amino acids decreased from $12.5 \pm 0.5 \mathrm{mmol} \mathrm{gdw}^{-1}$ to $9.3 \pm 0.3 \mathrm{mmol} \mathrm{gdw}^{-1}$ with increasing $\mu$ (Additional file 2, Figure S1), exceeding two to three times that required for synthesis of proteins in biomass $(4.2 \pm 0.1$ mmol gdw ${ }^{-1}$, Additional file 1, Table S1), and constituting always $21 \pm 1 \%$ (52 to $39 \mathrm{C}$ - $\mathrm{mmol} \mathrm{gdw}^{-1}$ ) of all the total carbon utilised by cells throughout the $\mu$ range studied.

For proof of principle, a chemostat experiment was carried out at a dilution rate of $0.45 \mathrm{~h}^{-1}$ and the data obtained were compared with the data obtained at the same $\mu$ value in A-stat experiments. The measured substrate and product yields in chemostat culture had values in the range of presented standard deviations for A-stat data (Additional file 2, Table S2) which shows 
that quasi steady state data from A-stat is comparable to chemostat.

\section{Amino acid consumption profiles}

Based on amino acid concentrations in the cultivation broth, consumption patterns $\left(\mathrm{mmol}_{\mathrm{AA}} \mathrm{gdw}^{-1}\right)$ for all the 20 amino acids were calculated (Figure 2 and Additional file 2, Figure S2). The most abundantly consumed amino acid throughout the $\mu$ range studied was glutamine (Additional file 2, Figure S2). Asparagine, arginine, serine, threonine, alanine, leucine, isoleucine and cysteine were the next most intensively consumed amino acids which consumption exceeded notably the amounts necessary for biomass formation. Lysine, phenylalanine and valine were consumed in slightly higher amounts than needed for biomass production. Consumption of aspartate, histidine, and proline were in the range of measurement errors, hence, their consumption can be considered minimal or nonexistent. It has been shown that the latter amino acids are non-essential for the growth of L. lactis [8].

In more detail, specific growth rate dependent consumptions of asparagine, threonine and cysteine per biomass were constant in the $\mu$ range of $0.10-0.20 \mathrm{~h}^{-1}$, but decreased 30 to $40 \%$ from $\mu=0.20 \mathrm{~h}^{-1}$ until $\mu_{\max }$ value (Figure 2 and Additional file 2, Figure S2). Consumption of arginine decreased rapidly in the $\mu$ range of 0.10 $0.35 \mathrm{~h}^{-1}$ from $2.15 \pm 0.04 \mathrm{mmol} \mathrm{gdw}^{-1}$ and levelled at $0.44 \pm 0.07 \mathrm{mmol} \mathrm{gdw}^{-1}$ at higher growth rates (Figure 2) - at an amount greater than necessary for biomass production $\left(0.20 \pm 0.02 \mathrm{mmol} \mathrm{gdw}^{-1}\right)$. Decreasing trends in the $\mu$ range $0.10-0.35 h^{-1}$ were observed for the production of ornithine and for the production of the only amino acid produced - glutamate. Glycine was the only amino acid which consumption increased during increasing $\mu$ (Figure 2), however, its consumption was always lower than its need for biomass formation. Consumption of other amino acids (Gln, Ile, His, Leu, Lys,
Met, Phe, Tyr, Trp, Val) did not change significantly throughout the studied $\mu$ range, indicating also a more efficient use of amino acids at higher $\mu$ values as growth yields based on carbon and nitrogen consumption increased.

\section{Carbon, nitrogen and ATP balances}

Carbon recovery which was calculated based on glucose and amino acid consumptions, product and biomass formation was $100 \pm 2 \%$ over the entire $\mu$ range (Additional file 2, Figure S3). However, nitrogen recovery, calculated based on amino acid utilization and ornithine, glutamate and biomass formation, was $55 \pm 3 \%$ (Additional file 2, Figure S3). Amino acids were the main nitrogen source in the medium, comprising more than $99 \%$ of the consumed nitrogen by the cultivated bacterium. Based on amino acid utilization, the total consumption of nitrogen decreased from 22 to $14 \mathrm{mmol} \mathrm{gdw}^{-1}$ between the $\mu$ range $0.10-0.59$ $\pm 0.02 \mathrm{~h}^{-1}$. On the basis of monomer composition, $\mathrm{N}$-molar content in the biomass was found to be constant at $7.2 \mathrm{mmol} \mathrm{gdw}^{-1}$ during the studied $\mu$ range. Concomitantly, nitrogen incorporation into the biomass increased from 33 to $50 \%$ from total consumed nitrogen in amino acids with increasing $\mu$. The rest of nitrogen (50-67\%) could have been metabolised through arginine deiminase (ADI) pathway, by excreting other amino acids (glutamate, aspartate) or through deamination reactions (ammonium). Activity of the ADI pathway decreased in the $\mu$ range $0.10-0.35 \mathrm{~h}^{-1}$ and nitrogen excretion to ornithine and synthesis of exogenous $\mathrm{NH}_{3}$ declined from 4.7 to $0.5 \mathrm{mmol}$ $\mathrm{gdw}^{-1}$ (21 to $4 \%$ from total nitrogen consumed) in the above $\mu$ range. In addition, 0.4 to $0.06 \mathrm{mmol} \mathrm{gdw}^{-1}$ of nitrogen was excreted as glutamate and $0.1 \mathrm{mmol} \mathrm{gdw}^{-1}$ through transamination reactions with the formation of the following compounds detected and quantified by mass-spectrometry: 4-hydroxyphenylpyruvic acid, hydroxyphenyllactic acid, 2-hydroxy-3-methylbutyric acid, 2-hydroxyisocaproic acid and L-3-phenyllactic acid from tyrosine,
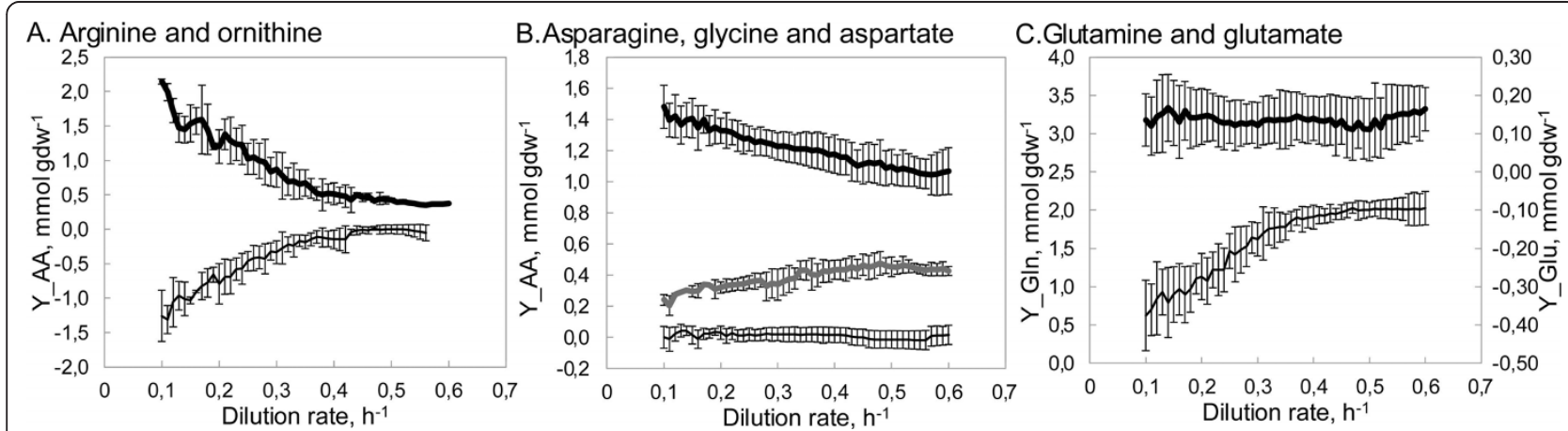

Figure 2 L. lactis dilution rate dependent amino acid consumptions ( $\mathrm{mmol} \mathrm{gdw}^{-1}$ ) for (A) arginine (thick line) and ornithine (thin line); (B) asparagine (thick line), glycine (dashed line) and aspartate (thin line); (C) glutamine (thick line) and glutamate (thin line). Negative numbers on chart represent production. Refer to Additional file 2, Figure S2 for consumption yields of all amino acids. 
phenylalanine or branched chain amino acids (data not shown). The left-over of consumed nitrogen was 9.5 - 6.6 mmol gdw ${ }^{-1}$ (contributing $44-48 \%$ from total nitrogen) in the $\mu$ range of $0.1-0.6 h^{-1}$. This nitrogen must have been excreted as $\mathrm{NH}_{3}$ if the excess of consumed amino acids not incorporated into protein fraction of biomass would have been converted to pyruvate. The latter assumption is supported by the fact that the carbon was fully recovered during the growth. Reduction of carbon and nitrogen wasting led to the increase of the biomass yields based on carbon (including glucose and amino acids) and nitrogen consumption 1.3 and 1.5 times,

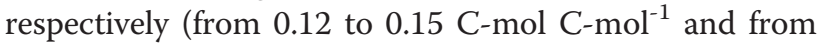
0.33 to $0.50 \mathrm{~N}-\mathrm{mol} \mathrm{N}-\mathrm{mol}^{-1}$ ), in parallel with the increase of $\mu$ from 0.10 to $0.59 \pm 0.02 \mathrm{~h}^{-1}$.

Based on biomass monomer composition and the stoichiometry of ATP, NAD(P)H and central metabolites for monomer production, $\mu$ dependent ATP and NAD $(\mathrm{P}) \mathrm{H}$ balance calculations were carried out (Additional file 1, Tables S3-S5). Calculations indicated that more ATP was produced than necessary for biomass formation. Presumably the ATP synthesized in excess was wasted in futile cycles. Calculated energy spilling was constant at 60 mmol ATP $\mathrm{gdw}^{-1}$ in the range of the $\mu 0.10-0.15 \mathrm{~h}^{-1}$ and decreased afterwards to $36 \mathrm{mmol} \mathrm{gdw}^{-1}$ at $\mu_{\max }$, indicating that the metabolism was the most efficient near $\mu_{\max }$ conditions (Additional file 1, Table S5). Similarly calculated $\mathrm{NAD}(\mathrm{P}) \mathrm{H}$ misbalance (spilling) decreased from $3.5 \mathrm{mmol} \mathrm{gdw}^{-1}$ at low growth rates to $0 \mathrm{mmol}$ $\mathrm{gdw}^{-1}$ at specific growth rate $>0.45 \mathrm{~h}^{-1}$ (Additional file 1 , Table S5). However, latter improvement of balance is inside the range of errors of lactate measurements (as lactate dehydrogenase is the main NAD regeneration reaction in lactic acid bacteria). Therefore a conclusion that redox balance was maintained throughout the studied growth conditions should be drawn.

\section{Transcriptome and proteome response}

Transcriptomes and proteomes at four different quasi steady state $\mu$ values $\left(0.17,0.24,0.44,0.52 \mathrm{~h}^{-1}\right)$ were compared to steady state $\mu=0.10 \mathrm{~h}^{-1}$ (additional info in Methods). Changes in gene and protein expression levels for the most relevant reactions between $\mu 0.52$ and $0.10 \mathrm{~h}^{-1}$ are illustrated on Figure 3 and 4; a full list of measured gene and protein expression changes at various $\mu$ values can be found in Additional file 3. In this section we discuss changes of mRNA and protein expressions significant with $P$ value $\leq 0.05$ for $\mu 0.52 \pm 0.03 \mathrm{~h}^{-1}$ vs. $0.10 \mathrm{~h}^{-1}$.

Mannose uptake genes $p \operatorname{tn} A B$, which are responsible for glucose transport in L. lactis, and ptsI were upregulated 2.1 to 4.3 -fold at the transcriptome level at higher growth rates (above $0.44 \mathrm{~h}^{-1}$ ). However, corresponding enzymes did not show any remarkable change in the same growth rate range as measured in the proteome. Transporter genes for additional sugars (not present in our medium) like galactose (by galE) and cellobiose (by ptcABC and yidB) were 1.8 to 2.9 -fold down-regulated at higher specific growth rates at the transcriptome level, whereas a 2.2- to 2.8-fold repression of PtcAB was measured for proteome. This down-regulation is known to be the consequence of carbon catabolite repression which is extensively studied also in other bacteria like E. coli and B. subtilis $[15,16]$.

Expression in the upper part of glycolysis did not change significantly during increase of $\mu$. However, the lower part of glycolysis (from $f b a A$ to eno) was 1.8 - to 4-times up-regulated at the transcriptome level, but only Pmg showed significant 1.6-fold up-regulation at the proteome level at the growth rates higher than $0.44 \mathrm{~h}^{-1}$ (Figure 3). The pentose phosphate pathway showed a 1.3- to 2.0-fold down-regulation in genes deoBC, rpiA, $z w f$, $t k t, y w c C$ (Additional file 3), which might be explained by a lower NADPH requirements at higher $\mu$ conditions. Despite the down-regulation of pentose phosphate pathway, genes encoding proteins involved in purine and pyrimidine metabolism were up-regulated. Moderate, 1.5- to 3.0-fold up-regulation both at the transcriptome and proteome level of the operon PurABEFLMQ was observed. With the increase of purine and pyrimidine metabolism, the need for amino group transfer from glutamine should have been also increased with rising specific growth rate. In agreement with this, expression of the genes in the first steps of purine and pyrimidine synthesis, purF increased and car $A B$ remained constant respectively, with the increase of $\mu$. High glutamine availability was maintained presumably by increased expression of glutamine transporter $(g \ln Q P)$ and glutamine synthetase $(g \ln A)$.

Considering pyruvate metabolism, decreased acetate production was in accordance with the significant down-regulation of genes eutD and ackA2 and their corresponding enzymes (see Figure 3). However, decreased production of formate and lactate seemed not to be regulated similarly with acetate - Pfl and Ldh showed no major changes neither in gene nor protein expression levels confirming that $\mathrm{Ldh}$ is regulated rather by the $\mathrm{NADH} / \mathrm{NAD}^{+}$ratio than by transcription and/or translation, as proposed in literature [17]. Although ethanol production decreased, AdhE expression increased 7.3- and 1.8-fold in transcriptome and proteome analysis, respectively. This might be related to the incorporation of ethanol formation pathway intermediate, acetaldehyde, to acetyl-CoA synthesis from deoxyribose. Pyruvate dehydrogenase subunits (PdhABCD) were 2 - to 3-fold down-regulated at both levels (Figure 3).

It is well known, that L. lactis can direct part of the consumed (or de novo synthesised) serine into pyruvate by $s d a A$ and $i l v A$ - this flux could form up to $10 \%$ of overall 


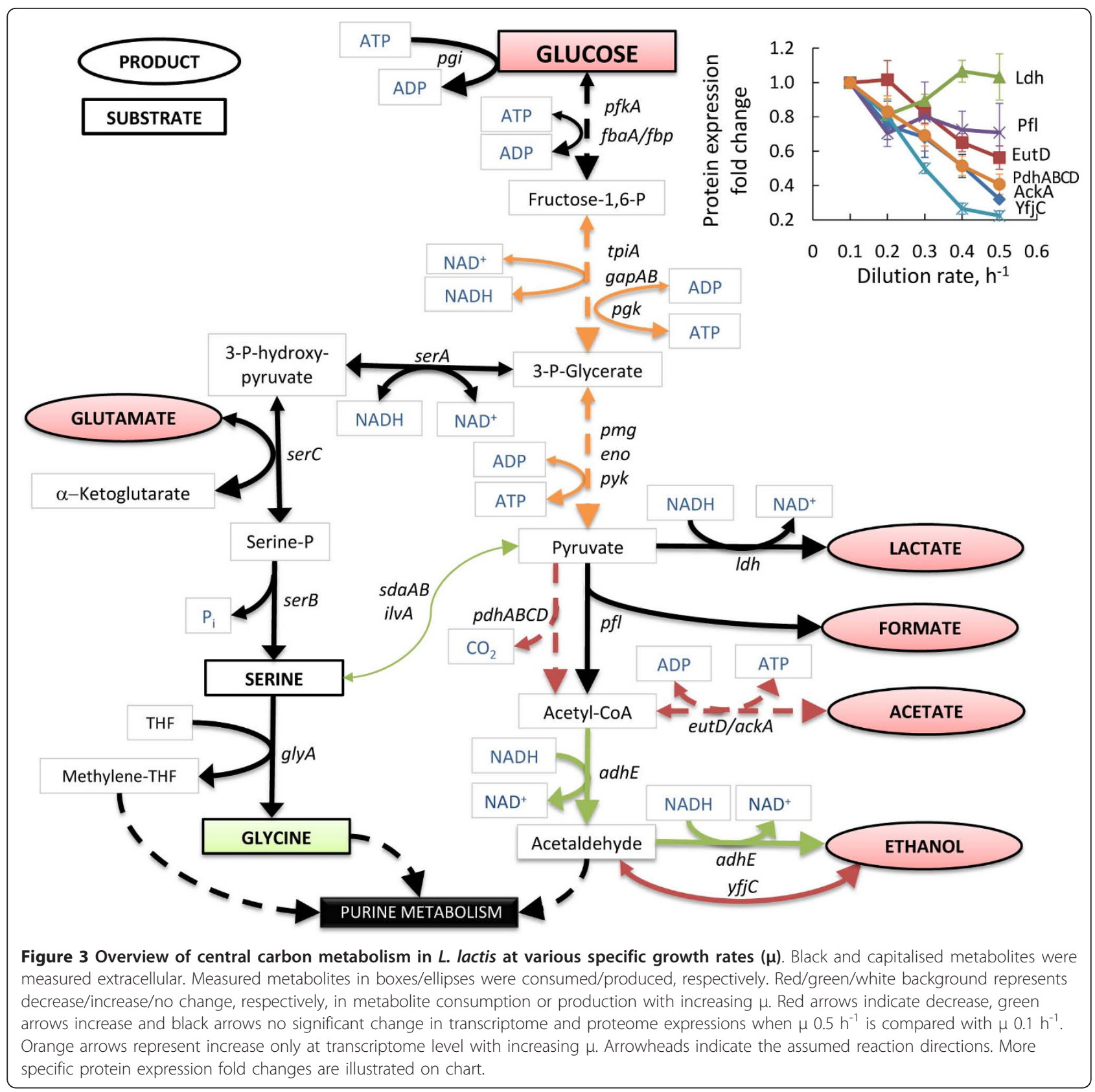

pyruvate flux [18]. In the current study, these noted genes were 1.4- to 2.2-fold up-regulated comparing $\mu=0.50$ to $\mu=0.10 \mathrm{~h}^{-1}$. In concordance with the sharp decrease of arginine consumption from $\mu 0.10 \mathrm{~h}^{-1}$ up to $\mu 0.35 \mathrm{~h}^{-1}$, the 2.3- to 4.5-fold decrease in protein expression of ArcAB, which converts arginine to ornithine, was observed during the increase of $\mu$ (Figure 4).

\section{Discussion}

\section{Carbon balance and growth efficiency}

Growth conditions have a strong influence on specific growth rate $(\mu)$, macromolecular composition of biomass (i.e. ribosomal content) and cell size of microorganisms $[18,19]$. In this study, a gradual change to more efficient carbon metabolism with the increase of $\mu$ was observed for L. lactis (Figure 1). The first shift in L. lactis metabolism took place at $\mu 0.20 \pm 0.02 \mathrm{~h}^{-1}$, when biomass yield $\left(\mathrm{Y}_{\mathrm{XC}}\right)$ per consumed carbon started to increase. Thirty percent increase with the increase of $\mu$ from 0.10 to 0.60 $\mathrm{h}^{-1}$ was achieved by reduction of fermentation by-products synthesis (acetate, formate, ethanol). Concomitantly to the increase of biomass yield, calculated ATP balance showed decreased energy spilling. It has been postulated that higher energy spilling at lower $\mu$ conditions could be 


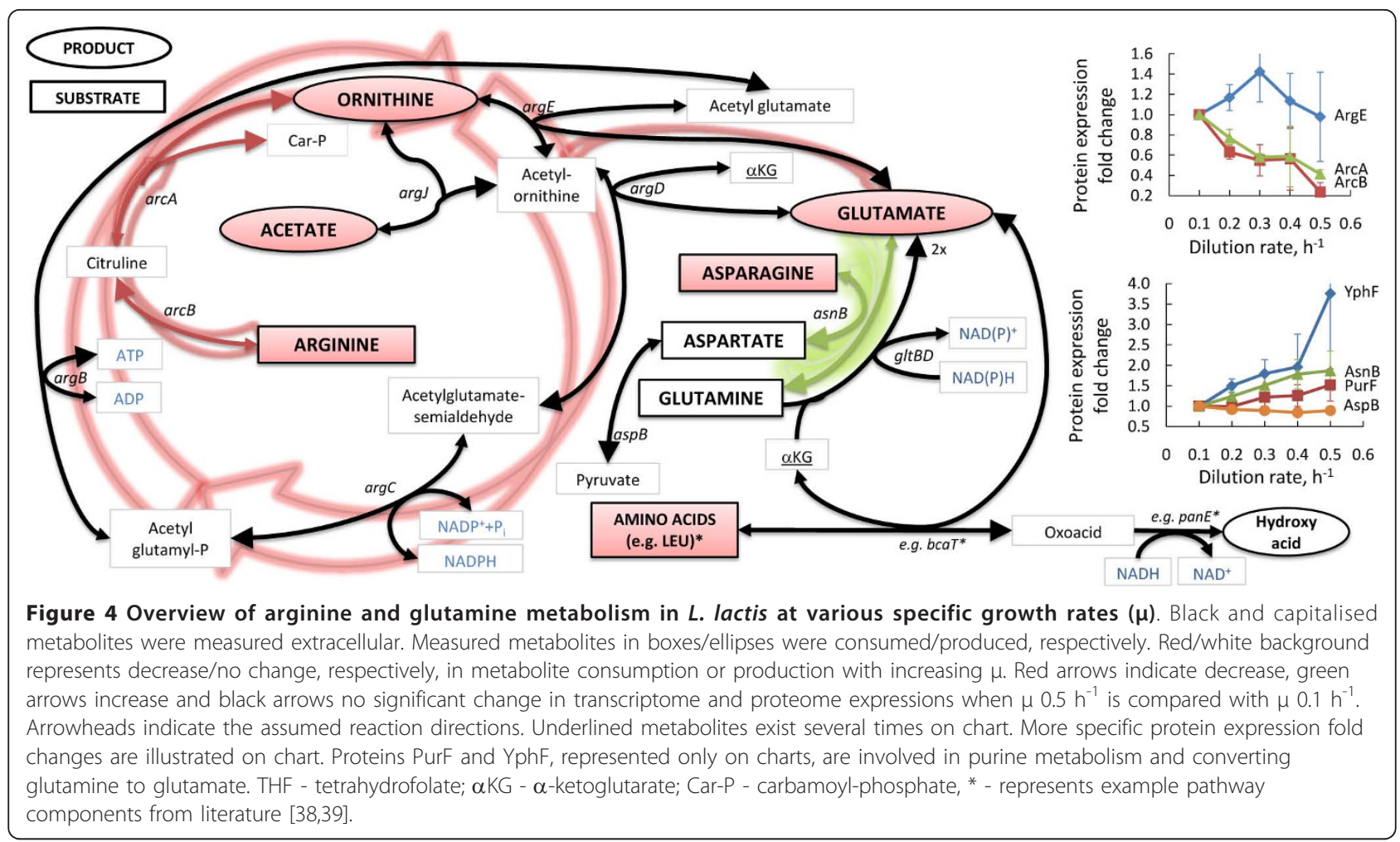

caused by greater costs of turnover of macromolecules and sensory molecules, establishment of ion gradients across the cell membrane etc [20]. Dressaire et al. [12] calculated the degradation rates for proteins and found that protein median half-lives were $c a$ 10-fold shorter at $\mu=0.10 \mathrm{~h}^{-1}$ than at $\mu_{\max }$. As ATP is consumed during protein degradation [21] this non-growth related expenditure might form a higher proportion of the total energy synthesized at lower $\mu$ conditions than at higher growth rates.

\section{Nitrogen metabolism}

With the increase of specific growth rate from 0.10 to $0.60 \mathrm{~h}^{-1}$ biomass yield $\mathrm{Y}_{\mathrm{XN}}$ increased 1.5 times showing that cells used nitrogen more effectively for biomass production. The most important amino acid that plays role in the observed reduction of nitrogen wasting was arginine (arginine consumption decreased from 1.5 to $0.5 \mathrm{mmol} \mathrm{gdw}^{-1}$ with increase of $\mu$ from 0.1 to $0.35 \mathrm{~h}^{-1}$ ). Throughout the $\mu$ range studied, arginine consumption was 0.3 to $1.3 \mathrm{mmol} \mathrm{gdw}^{-1}$ higher than spent for biomass synthesis and majority of the consumed arginine was transformed to ornithine (0.05 to $\left.1.2 \mathrm{mmol} \mathrm{gdw}^{-1}\right)$, especially at lower specific growth rates, which indicates energy limitation of cells. However, not all arginine left over from calculated requirements for biosynthesis $(0.1$ to $0.25 \mathrm{mmol} \mathrm{gdw}^{-1}$ ) was converted to ornithine. Based on annotated network of L. lactis there is no route for consumption of ornithine other than that leading to the synthesis of glutamate (mediated by ArgCDJFG, which were reduced with increase of specific growth rates especially after $0.4 \mathrm{~h}^{-1}$ ). Although the mechanisms of arginine overconsumption in addition to ornithine production are not known, correlation between ornithine production and glutamate synthesis was 0.99 , which shows that these syntheses were most probably coupled. Production of glutamate has also been observed before, when both glutamine and glutamate were present in the cultivation medium $[8,22]$.

Nitrogen wasting through glutamine metabolism was not decreased during the increase of specific growth rate. Glutamine, the most consumed amino acid (glutamine consumption covers 30 to $50 \%$ of total nitrogen consumed, at $\mu 0.10$ and $0.60 \mathrm{~h}^{-1}$, respectively), is used for synthesis of biomass proteins and it is the donor of amino groups in purine, pyrimidine and in aminosugar production pathways (glutamine and glutamate requirements for transamination reactions in aminosugar and nucleotide synthesis was in average $\left.1.35 \mathrm{mmol} \mathrm{gdw}^{-1}\right)$. It should be noted that glutamine synthetase $(g \ln A)$ was highly expressed (having array spot intensity values up to four times higher than these of average values of all genes) and increased with increase of $\mu$ in parallel to high consumption of the amino acid. Although we cannot argue over the direction of reactions on the basis of our experimental data, it could be assumed that maintenance of high intracellular concentrations of glutamine 
in the cells in the result of intense synthesis and consumption flows might be necessary to keep the transfer of amino group effective.

The third biggest part of nitrogen wasting could be associated with the consumption of asparagine, which was reduced from 1.4 to $1.1 \mathrm{mmol} \mathrm{gdw}^{-1}$ with increase of $\mu$ from 0.10 to $0.60 \mathrm{~h}^{-1}$. Asparagine and aspartate (which was not consumed and therefore should have been produced from asparagine) are required for syntheses of nucleotides (in average $0.35 \mathrm{mmol} \mathrm{gdw}^{-1}$ ) and proteins (in average $0.4 \mathrm{mmol} \mathrm{gdw}^{-1}$ ). It was shown that 0.35 to $0.65 \mathrm{mmol} \mathrm{gdw}^{-1}$ of asparagine was not used for biosynthesis. Asparagine can be metabolised through asparaginase $(a n s B)$ - however its expression was in the range of threshold values in the mRNA array and corresponding protein was not detected. Instead of that the high expression (array spot intensity values up to seven times higher than these of average values of all genes) of asparagine synthetase $(\operatorname{asn} B)$, which expression even increased with increase of specific growth rate was observed. Similarly to glutamine it could be assumed that overconsumption of asparagine and high expression of the relevant synthesis genes might be necessary to keep the transfer of amino group effective. Energetically transport of asparagine in L. lactis is much more efficient than aspartate [23], moreover, asparagine is probably preferentially directed towards the production of aspartate $[24,25]$. Surplus of aspartate in its turn can be directed into pyruvate by AspB (Figure 4).

The role of other amino acids (other than glutamine, arginine and aspartate) in nitrogen wasting can be considered minimal as over-consumptions (amounts greater than necessary for biomass production) of these amino acids were below $0.2 \mathrm{mmol} \mathrm{gdw}^{-1}$ (cysteine, serine, threonine) or $0.1 \mathrm{mmol} \mathrm{gdw}^{-1}$ (all other not mentioned above).

\section{Omics comparison}

Good correlation with a Pearson coefficient up to 0.69 was observed between 600 measured protein and gene expression data (Figure 5). An interesting phenomenon was seen at $\mu$ values $0.52 \pm 0.03 \mathrm{~h}^{-1}$ and $0.42 \pm 0.02 \mathrm{~h}^{-1}$ compared to $0.10 \mathrm{~h}^{-1}$ : a large amount of genes upregulated at the transcriptome level showed only small or no change at the proteome level (Figure 5). The vast majority of members in this group were related to ribosomal subunits $(74 \%$ from all detected ribosomal proteins), as well as lower glycolysis (FbaA, GapB, Pgk, Eno) and amino acid or peptide transport (BusAB, GlnPQ, GltPS, OptCD, PepCPX, PtnABD, PtsHI). Up-regulation at the transcriptome level and no significant change at proteome level during anaerobic growth of L. lactis in lower part of glycolysis have also been noticed before $[11,12]$. Despite the relatively good
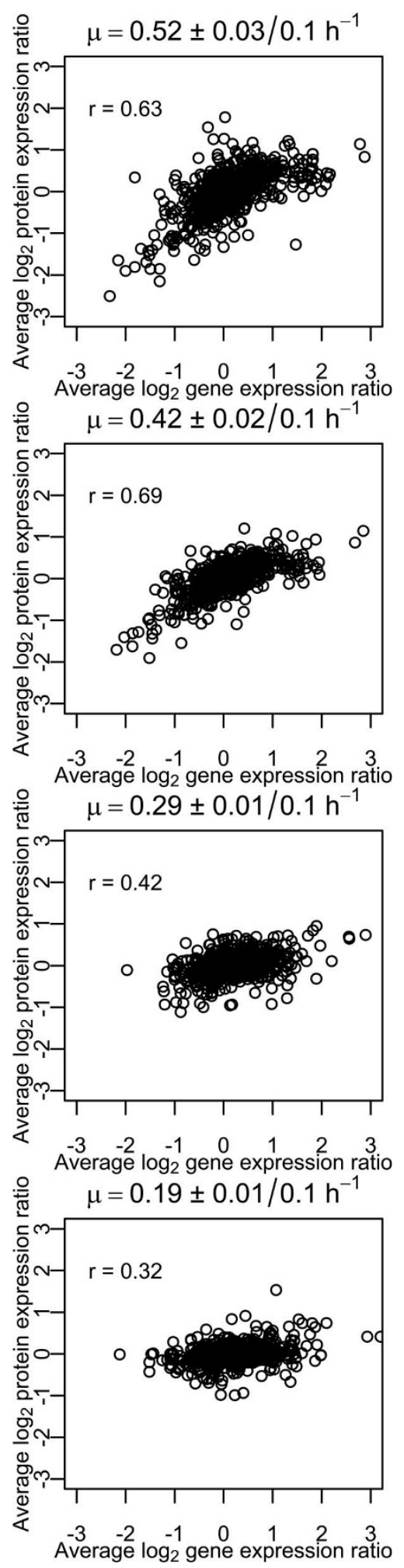

Figure $5 \mathrm{~L}$. lactis transcriptome and proteome correlation at various specific growth rates. " $\mathrm{R}$ " value on chart represents Pearson coefficient. Six hundred proteins, with a standard deviation less than $30 \%$ and their corresponding genes are indicated on a graph. 
correlation between the transcriptomic and proteomic data, several important regulations were observed only at trancriptome level. The data obtained indicated importance of taking into account the possibility of allosteric regulation, and carrying out measurements of fluxome in addition to transcriptome and proteome to fully characterize regulation of metabolic pathways.

By scanning the entire range of specific growth rates using A-stat experiments, it is possible to continuously monitor the steady state metabolism using on-line sensors or frequently collected samples for at-line analyses. Reproducibility of growth characteristics in A-stat were compared with chemostat at $\mu 0.45 \mathrm{~h}^{-1}$. All measured substrate consumption and product formation yields (including amino acids) remained within mentioned standard deviation ranges indicating the accordance of quasi steady state and steady state data (Additional file 2, Table S2). Recently, similar comparisons at the global transcriptome level were conducted with $E$. coli achieving very good correlation with a Pearson coefficient up to 0.96 [26]. In both studies, it was shown that the A-stat cultivation technique allows precise monitoring the sequence of metabolic switch points.

\section{Conclusions}

Distinct ratios of glucose and amino acids in the growth media are very important for biomass yield optimization as carbon and nitrogen metabolism are tightly coupled in L. lactis. High biomass yields are crucial for producing vaccines using microorganisms and nutrient limitations can strongly affect achieving the desired results. As was shown in this study, some amino acids were consumed in large amounts (glutamine, asparagine, arginine) and more efficient growth might not be achieved by insufficient supply of these compounds. There have been several attempts to optimize the media for lactococci using a single omission technique $[7,8]$, however, a systematic approach taking into account that amino acid requirements depend on environmental conditions (e.g. at various $\mu$ values) has not yet been fully realized as it is difficult using only batch cultivation. The current work combining systematic continuous cultivation approach with omics methods is therefore of high value for better media design, as well as for understanding principles of metabolism of the bacteria.

Using steady state cultivation methods and a systems biology approach for characterisation of L. lactis metabolism, it was possible to demonstrate a shift to more efficient metabolism at higher growth rates by increasing the biomass yield, change towards homolactic fermentation, and decreasing the flux through alternative energy generation pathways with lower efficiency than glycolysis e.g. acetate formation and the ADI pathway.
This study demonstrates the necessity of using strictly controlled continuous cultivation methods in combination with a multi-omics approach and element balance calculations to gain quantitative understanding of the regulation of complex global metabolic networks, important for strain dependent media optimisation or the design of efficient producer cells. However, questions about rationale of 2-3 times over-consumption of amino acids by cells and principles of properly balanced media remain to be answered in full in the future studies.

\section{Methods}

\section{Microorganism and medium}

The strain used throughout these experiments Lactococcus lactis subsp. lactis IL1403 was kindly provided by Dr. Ogier from INRA (Jouy-en-Josas, France). Inoculum was prepared using a lyophilized stock culture stored at $-80^{\circ} \mathrm{C}$ which was pre-grown twice on the cultivation medium. Chemically defined medium with a reduced amino acid concentrations were developed especially for better detection of amino acids. Media contained 70\% GIBCO ${ }^{\mathrm{TM}}$ F-12 Nutrient Mixture (Invitrogen Corporation, Carlsbad, CA) and 30\% modified CDM (composition in [27]). This combination gave the best trade-off for growth yield and maximal growth rate. Composition of the final medium was as follows $\left(\mathrm{mg} \mathrm{L}^{-1}\right)$ : limiting substrate D-Glucose - 3500; L-Alanine - 78; L-Arginine - 185; L-Asparagine - 74; L-Aspartic acid - 72; L-Cysteine - 64; L-Glutamic acid - 70; L-Glutamine - 132; Glycine - 58; L-Histidine - 60; L-Isoleucine - 102; L-Leucine - 207; L-Lysine - 158; L-Methionine - 41; L-Phenylalanine - 86; L-Proline - 92; L-Serine - 163; LThreonine - 76; L-Trypthophan - 16; L-Tyrosine - 29; L-Valine - 107; Biotin - 0.305; Choline chloride - 9.8; D-Pantothenate - 0.65; Folic Acid - 1.21; Niacinamide 0.325; Pyridoxine hydrochloride - 0.642; Riboflavin - 0.326; Thiamine hydrochloride - 0.51; Vitamin B12 - 0.98; i-Inositol - 12.6; $\mathrm{CaCl}_{2}-28 ; \mathrm{CuSO}_{4} \times 5 \mathrm{H}_{2} \mathrm{O}-0.272 ; \mathrm{FeSO}_{4} \times$ $7 \mathrm{H}_{2} \mathrm{O}-0.71 ; \mathrm{MgCl}_{2}-58 ; \mathrm{KCl}-157 ; \mathrm{NaCl}-5580 ; \mathrm{Na}_{2} \mathrm{PO}_{4}$ - 99; $\mathrm{ZnSO}_{4} \times 7 \mathrm{H}_{2} \mathrm{O}-1$; Hypoxanthine- $\mathrm{Na}-3$; Linoleic Acid - 0.1; Lipoic Acid - 0.1; Phenol Red - 0.8; Putrescine $\times$ $2 \mathrm{HCl}-0.1 ;$ Na-Pyruvate - 77; Thymidine - 0.5 .

\section{A-stat cultivations}

A-stat cultivations were carried out in a $1 \mathrm{~L}$ Biobundle bioreactor (Applikon, Schiedam, the Netherlands) controlled by an ADI1030 biocontroller (Applikon) and a cultivation control program "BioXpert NT" (Applikon) (detailed description in [28], with an addition of an in situ OD sensor (model TruCell2; Finesse, San Jose, CA)). Cultivations were carried out under anaerobic conditions $\left(\mathrm{N}_{2}\right.$-environment) with an agitation speed of $300 \mathrm{rpm}$ at $34^{\circ} \mathrm{C}$ and $\mathrm{pH}$ 6.4. Five parallel A-stat experiments were carried out where after a batch phase, 
constant dilution rate $\left(\mathrm{D}=0.1 \mathrm{~h}^{-1}\right)$ was initiated. Culture was stabilised until constant optical density and titration rate, pumping through at least 5 volumes of medium. After achieving steady state conditions, acceleration of dilution rate $\left(\mathrm{a}=0.01 \mathrm{~h}^{-2}\right)$ was started. Additionally, a steady state chemostat experiment was carried out at a dilution rate of $0.45 \mathrm{~h}^{-1}$ and results were compared with data collected from the A-stat experiment at the same dilution rate. Average yield and metabolic switch point values with their standard deviations were calculated based on five independent experiments, additionally taking into account chemostat experiment values at a dilution rate of $0.45 \mathrm{~h}^{-1}$.

\section{Analytical methods and growth characteristics}

Biomass was constantly monitored by measuring the optical density at $600 \mathrm{~nm}$; biomass dry weight was determined gravimetrically. Biomass correlation constant $\mathrm{K}$ was $0.372 \pm 0.005$ and was not specific growth rate dependent. Levels of glucose, lactate, formate, acetate and ethanol in the culture medium were measured with liquid chromatography (Alliance 2795 system, Waters Corp., Milford, MA), using a BioRad HPX-87H column (Hercules, CA) with isocratic elution of $5 \mathrm{mM} \mathrm{H}_{2} \mathrm{SO}_{4}$ at a flow rate of 0.6 $\mathrm{mL} \mathrm{min}^{-1}$ and at $35^{\circ} \mathrm{C}$. A refractive index detector (model 2414; Waters Corp.) was used for detection and quantification of substances. The detection limit for the analytical method was $0.1 \mathrm{mM}$. Samples from culture medium were centrifuged $(14,000 \times g, 4 \mathrm{~min})$; supernatants were collected and analyzed immediately or stored at $-20^{\circ} \mathrm{C}$ until analysis. Free amino acid concentrations were determined from the same sample (analysing frequency ca $0.02 \mathrm{~h}^{-1}$ ) with an amino acid analyzer (Acquity UPLC; Waters Corp.) according to the manufacturer's instructions. Empower software (Waters Corp.) was used for the data processing. For measuring amino acid concentrations in protein content, biomass was hydrolysed with $6 \mathrm{M} \mathrm{HCl}$ for $20 \mathrm{~h}$ at $120^{\circ} \mathrm{C}$. From hydrolyte, amino acids were determined as free amino acids described above. Protein content from biomass dry cell weight was calculated based on amino acid analysis and, additionally, measured using the Lowry method [29], where bovine serum albumin was used as a standard. For measurement of DNA content in biomass genomic DNA was extracted and measured using instructions of RTP $^{\circledR}$ Bacteria DNA Mini Kit (Invitec, Germany). Detailed protocol for fatty acid quantification is described in [30]. Growth characteristics $\mu, \mathrm{Y}_{\mathrm{XS}}, \mathrm{Y}_{\text {Substrate, }}$ $Y_{\text {Product }}$ were calculated as described previously $[27,28]$. For consumption calculations, measured medium concentrations were used.

\section{Carbon, nitrogen and ATP balance calculations}

For carbon balance calculations C-molar concentrations of measured substrates, products and biomass were used (biomass C-molar concentration with a value 0.03625 C-mol gdw ${ }^{-1}$ was calculated based on monomer composition). For nitrogen balance calculations $\mathrm{N}$-molar amino acid consumptions, production of ornithine and glutamate, ADI pathway activity and biomass composition $\left(0.00725 \mathrm{~N}-\mathrm{mol} \mathrm{gdw}^{-1}\right)$ were taken into account.

For calculations of ATP and NAD(P)H balance measured biomass, amino acid, RNA, DNA and fatty acid contents were used. Other necessary data were adapted from literature [31]. Stoichiometry of ATP, NAD(P)H and central metabolites for monomer production were taken from the Kyoto Encyclopaedia of Genes and Genomes database http://www.kegg.jp/, with an assumption that amino acids were not synthesized. Specific calculations are presented in Additional file 1.

\section{Gene expression profiling}

Agilent's DNA microarrays (Santa Clara, CA) were designed in eArray web portal in $8 \times 15 \mathrm{~K}$ format, containing 7 unique probes per target https://earray.chem. agilent.com/earray/. Target sequences for 2234 genes were downloaded from Kyoto Encyclopaedia of Genes and Genomes ftp://ftp.genome.jp/pub/kegg/genes/organisms/lla/l.lactis.nuc.

For microarray analysis, steady state chemostat culture of $L$. lactis IL1403 was used as reference $\left(D=0.10 \mathrm{~h}^{-1}\right)$. Subsequent quasi steady state points from A-stat experiment at specific growth rates $0.52 \pm 0.03 ; 0.42 \pm 0.02$; $0.29 \pm 0.01 \mathrm{~h}^{1}$ in biological duplicates and $0.17 \mathrm{~h}^{-1}$ were compared to the reference sample. Transcript change was considered significant if the $P$ value between parallel experiments was less than 0.05 .

Total RNA was extracted and quantified, cDNA synthesised and labelled as described previously [27], with minor modification: $11 \mu \mathrm{g}$ of total RNA was used for cDNA synthesis. Hybridization, slide washing and scanning was performed using standard Agilent's reagents and hardware http://www.chem.agilent.com. Gene expression data was analyzed as described before [27], except global lowess normalization was used. Spots with intensities lower than 100 units in both channels and outliers among technical replicates (according [32]) were filtered. After filtering, seven technical replicates showed average standard deviation $<10 \%$. Gene (and protein) expression measurement results are shown in Additional file 3. DNA microarray data is also available at NCBI Gene Expression Omnibus (Reference series: GSE26536).

\section{Protein expression profiling}

For protein expression analysis, the steady state chemostat culture of L. lactis IL1403 was used as reference $\left(\mu=0.10 \mathrm{~h}^{-1}\right)$. Quasi steady state points at $\mu=0.20 \pm$ $0.01,0.30 \pm 0.02,0.42 \pm 0.01$ and $0.50 \pm 0.01 \mathrm{~h}^{-1}$ were 
compared with the reference sample. Three biological replicates were analysed.

Samples intended for proteome analysis were collected, washed with PBS $(0.137 \mathrm{M} \mathrm{NaCl}, 2.7 \mathrm{mM} \mathrm{KCl}$, $10.0 \mathrm{mM} \mathrm{Na} 2 \mathrm{HPO}_{4}, 1.4 \mathrm{mM} \mathrm{KH_{2 }} \mathrm{PO}_{4}$ ), flash frozen in liquid nitrogen and stored at $-80^{\circ} \mathrm{C}$ prior to protein extraction.

Proteins were extracted in ice-cold SDS-buffer (100 mM Tris- $\mathrm{HCl}(\mathrm{pH}$ 6.5), 1\% SDS (w/v)). Cells were disrupted as a result of agitating the suspension with glass-beads at $4^{\circ} \mathrm{C}$ for 30 minutes. After centrifugation for $30 \mathrm{~min}$ at $4^{\circ} \mathrm{C}$, the supernatant was collected and the protein concentration was determined by 2D Quant kit (Amersham Biosciences, Buckinghamshire, UK) and protein samples were stored at $-80^{\circ} \mathrm{C}$ until further analysis.

Aliquots of $100 \mu \mathrm{g}$ cloroform/MeOH chloroform precipitated proteins from each sample were processed for labeling with iTRAQ 4plex reagents (Applied Biosystems, Foster City, CA) according to manufacturer's instructions. Briefly, precipitated proteins were dissolved in $0.5 \mathrm{M}$ triethylammonium bicarbonate (TEAB) and $0.1 \%$ SDS, disulfide bonds were reduced in $5 \mathrm{mM}$ Tris-(2-carboxyethyl) phosphine (TCEP) for $1 \mathrm{~h}$ at $60^{\circ} \mathrm{C}$, followed by blocking cycteine residues in $10 \mathrm{mM}$ methyl methanethiosulfonate (MMTS) for $30 \mathrm{~min}$ at room temperature, before digestion with trypsin (1:40, enzyme to protein ratio) overnight at $37^{\circ} \mathrm{C}$. For labeling, each iTRAQ reagent was dissolved in $70 \mu \mathrm{l}$ of ethanol and added to the respective peptide mixture. After $1 \mathrm{~h}$ incubation at room temperature the reactions were stopped by adding $100 \mu \mathrm{l}$ milliQ water and incubating for 30 min. All four samples were mixed together and ethanol was removed by drying in a vacuum concentrator (Model 5301, Eppendorf, Cambridgeshire, UK).

The combined peptide mixtures were separated into 10 fractions with a cation exchange cartridge system (Applied Biosystems, Foster City, CA) by different $\mathrm{KH}_{2} \mathrm{PO}_{4}$ concentrations (10-1000 mM) and cleaned by StageTips [33]. All fractions were analyzed twice by LC-MS/MS using an Agilent 1200 series nanoflow system (Agilent Technologies, Santa Clara, CA) connected to a Thermo Scientific LTQ Orbitrap mass-spectrometer (Thermo Electron, San Jose, CA) equipped with a nanoelectrospray ion source (Proxeon, Odense, Denmark). Purified peptides were dissolved in $0.5 \%$ formic acid and loaded on self-packed fused silica emitter $(150 \mathrm{~mm} \times$ $0.075 \mathrm{~mm}$; Proxeon) packed with Repropur-Sil C18-AQ 3 $\mu \mathrm{m}$ particles (Dr. Maisch, Germany) using a flow rate of $0.7 \mu \mathrm{min}^{-1}$. Peptides were separated with a $180 \mathrm{~min}$ gradient from 3 - 40\% B (A: 0.1\% formic acid, B: 0.1\% formic acid/80\% acetonitrile) using a flow-rate of $200 \mathrm{nl} \mathrm{\textrm {min } ^ { - 1 }}$ and sprayed directly into LTQ Orbitrap massspectrometer operated at $180^{\circ} \mathrm{C}$ capillary temperature and $2.4 \mathrm{kV}$ spray voltage.
Mass spectrometry method combined HCD and CID spectrums as described in Köcher et al. [34]. Briefly, full mass spectra were acquired in profile mode, with mass range from $\mathrm{m} / \mathrm{z} 300$ to 1800 at resolving power of 60000 (FWHM). Up to four data-dependent MS/MS scans with CID and four scans with HCD tandem mass spectrometry experiment triggered from the same precursor ion were acquired in centroid mode for each FTMS full-scan spectrum. CID was carried out with a target signal value of 10000 in the linear ion trap, collision energy of $35 \%$, Q value of 0.25 and an activation time of $30 \mathrm{~ms}$. HCD-generated ions were detected in the Orbitrap using the target signal value of 10000 , collision energy of $35 \%$ and an activation time of $40 \mathrm{~ms}$. Each fragmented ion was dynamically excluded for $60 \mathrm{~s}$.

Raw files were extracted to .mgf files by MM File Conversion Tools http://searcher.rrc.uic.edu/cgi-bin/ mm-cgi/downloads.py. Each .mgf file was converted to a QuantMerge file [34]. All files from the same sample were merged together. Data generated was searched against L. lactis IL1403 NCBI database (22092009) by MassMatrix search tool [35]. A reversed decoy database was used for false positives detection. In all cases, a peptide mass tolerance of $5 \mathrm{ppm}$ was used and fragment ion masses were searched with a $0.6 \mathrm{Da}$ mass window. Two missed cleavage sites for trypsin were allowed. Betamethylthiolation of a cysteine was set as a fixed modification and oxidation of methionine as a variable modification. Quantification was set as iTRAQ and quantification statistics as arithmetic mean. Only proteins with confidence intervals of more than $95 \%$ were allowed for further data analysis (Additional file 3). Proteomic analysis raw data is available at the PRIDE database [36]http://www.ebi.ac.uk/pride under accession numbers 13105-13162 (username: review17185, password: wyd"b6_6). The data was converted using PRIDE Converter http://code.google.com/p/pride-converter[37]. Protein expression change was considered significant if the $P$ value between parallel experiments was less than 0.05 .

\section{Additional material}

Additional file 1: Specific growth rate dependent ATP and NAD(P)H balance calculations for A-stat experiments with Lactococcus lactis subsp. lactis IL1403.

Additional file 2: Supplementary figures and tables

Additional file 3: Specific growth rate dependent mRNA and protein expression changes from A-stat experiments with

Lactococcus lactis subsp. lactis IL1403. The expression fold change is given accordingly: sample at respective specific growth rate (quasi steady state) is divided by steady state chemostat sample (0.10 h-1). Average $\log 2$ gene and protein expression changes were calculated from " $n$ " number of parallel A-stat experiments. In gene expression analysis spots with intensities lower than 100 units in both channels and outliers among technical replicates (according Rorabacher, 1991) were filtered. In 
protein expression analysis, proteins identified with a confidence interval more the $95 \%$ and appearances in all mentioned parallels are presented.

\section{Acknowledgements}

The authors would like to thank Lauri Peil (University of Tartu) and Elina Pelonen (Turku University of Applied Sciences and Åbo Akademi) for their help in carrying out 'omics analysis. The financial support for this research was provided by the European Regional Development Fund project EU29994, and Ministry of Education, Estonia, through the grant SF0140090s08

\section{Author details}

'Tallinn University of Technology, Department of Chemistry, Akadeemia tee 15, 12618 Tallinn, Estonia. ${ }^{2}$ Competence Center of Food and Fermentation Technologies, Akadeemia tee 15b, 12618 Tallinn, Estonia. ${ }^{3}$ Tallinn University of Technology, Department of Food Processing, Ehitajate tee 5, 19086 Tallinn, Estonia.

\section{Authors' contributions}

PJL, KAd, RV designed experiments and conceived the project. PJL, KAI carried out experiments. PJL, RN, LA, KAl contributed in analytics and data analysis. KAd was responsible for mathematical calculations. PJL drafted the manuscript. KAd helped drafting the manuscript. RV, RN, LA edited the manuscript. All authors read and approved the final manuscript.

\section{Competing interests}

The authors declare that they have no competing interests.

Received: 13 July 2010 Accepted: 24 February 2011

Published: 24 February 2011

\section{References}

1. Bolotin A, Wincker P, Mauger S, Jaillon O, Malarme K, Weissenbach J, Ehrlich SD, Sorokin A: The complete genome sequence of the lactic acid bacterium Lactococcus lactis ssp. lactis IL1403. Genome Research 2001, 11:731-53

2. Hugenholtz J, Sybesma W, Groot MN, Wisselink W, Ladero V, Burgess K, van Sinderen D, Piard JC, Eggink G, Smid EJ, Savoy G, Sesma F, Jansen T, Hols P, Kleerebezem M: Metabolic engineering of lactic acid bacteria for the production of nutraceuticals. Antonie Van Leeuwenhoek 2002, 82:217-35.

3. Kleerebezem M, Boels IC, Groot MN, Mierau I, Sybesma W, Hugenholtz J: Metabolic engineering of Lactococcus lactis: the impact of genomics and metabolic modelling. J Biotechnol 2002, 98:199-213.

4. Hugenholtz J: The lactic acid bacterium as a cell factory for food ingredient production. Intern Dairy J 2008, 18:466-75.

5. Morello E, Bermúdez-Humarán LG, Llull D, Solé V, Miraglio N, Langella P, Poquet I: Lactococcus lactis, an efficient cell factory for recombinant protein production and secretion. J Mol Microbiol Biotechnol 2008, 14:48-58.

6. Bermúdez-Humarán LG: Lactococcus lactis as a live vector for mucosal delivery of therapeutic proteins. Human Vaccines 2009, 5:264-7.

7. Jensen PR, Hammer K: Minimal Requirements for Exponential Growth of Lactococcus lactis. Appl Environ Microbiol 1993, 59:4363-6.

8. Novak L, Cocaign-Bousquet M, Lindley N, Loubiere P: Metabolism and energetics of Lactococcus lactis during growth in complex or synthetic media. Appl Environ Microbiol 1997, 63:2665-70.

9. Zhang G, Block DE: Using highly efficient nonlinear experimental design methods for optimization of Lactococcus lactis fermentation in chemically defined media. Biotechnol Prog 2009, 25:1587-97.

10. Larsen N, Boye M, Siegumfeldt H, Jakobsen M: Differential expression of proteins and genes in the lag phase of Lactococcus lactis subsp. lactis grown in synthetic medium and reconstituted skim milk. Appl Envir Microbiol 2006, 72:1173-9.

11. Mazzoli R, Pessione E, Dufour M, Laroute V, Giuffrida M, Giunta C, CocaignBousquet $\mathrm{M}$, Loubière $\mathrm{P}$ : Glutamate-induced metabolic changes in Lactococcus lactis NCDO 2118 during GABA production: combined transcriptomic and proteomic analysis. Amino Acids 2010, 3:727-37.
12. Dressaire $C$, Redon $E$, Milhem $H$, Besse $P$, Loubière $P$, Cocaign-Bousquet $M$ Growth rate regulated genes and their wide involvement in the Lactococcus lactis stress responses. BMC Genomics 2008, 9:343.

13. Dressaire C, Gitton C, Loubière P, Monnet V, Queinnec I, CocaignBousquet M: Transcriptome and proteome exploration to model translation efficiency and protein stability in Lactococcus lactis. PLoS Comput Biol 2009, 5:12.

14. Poolman B, Konings WN: Relation of growth of Streptococcus lactis and Streptococcus cremoris to amino acid transport. J Bacteriol 1988, 170:700-707

15. Görke B, Stülke J: Carbon catabolite repression in bacteria: many ways to make the most out of nutrients. Nat Rev Microbiol 2008, 6:613-24.

16. Titgemeyer F, Hillen W: Global control of sugar metabolism: a grampositive solution. Antonie Van Leeuwenhoek 2002, 82:59-71.

17. Garrigues C, Loubiere P, Lindley ND, Cocaign-Bousquet M: Control of the shift from homolactic acid to mixed-acid fermentation in Lactococcus lactis: predominant role of the $\mathrm{NADH} / \mathrm{NAD}^{+}$ratio. J Bacteriol 1997, 179:5282-7.

18. Novak L, Loubiere P: The metabolic network of Lactococcus lactis: Distribution of ${ }^{14} \mathrm{C}$-labeled substrates between catabolic and anabolic pathways. J Bacteriol 2000, 182:1136-1143.

19. Molenaar D, van Berlo $R$, de Ridder D, Teusink B: Shifts in growth strategies reflect tradeoffs in cellular economics. Mol Syst Biol 2009, 5:323.

20. Russell JB: The energy spilling reactions of bacteria and other organisms. J Mol Microbiol Biotechnol 2007, 13:1-11.

21. Ogura T, Wilkinson AJ: AAA+ superfamily ATPases: common structure diverse function. Gen Cells 2001, 6:575-597.

22. Smid EJ, Konings WN: Relationship between utilization of proline and proline-containing peptides and growth of Lactococcus lactis. J Bacteriol 1990, 172:5286-92

23. Benthin S, Villadsen J: Amino acid utilization by Lactococcus lactis subsp. cremoris FD1 during growth on yeast extract or casein peptone. J Appl Microbiol 1996, 80:65-72.

24. Lapujade P, Cocaign-Bousquet M, Loubiere P: Glutamate biosynthesis in Lactococcus lactis subsp. lactis NCDO 2118. Appl Envir Microbiol 1998 64:2485-9.

25. Konings WN, Poolman B, Driessen AJ: Bioenergetics and solute transport in lactococci. Crit Rev Microbiol 1989, 16:419-76.

26. Valgepea K, Adamberg K, Nahku R, Lahtvee PJ, Arike L, Vilu R: Systems biology approach reveals that overflow metabolism of acetate in Escherichia coli is triggered by carbon catabolite repression of acetylCoA synthetase. BMC Syst Biol 2010, 4:166.

27. Lahtvee PJ, Valgepea K, Nahku R, Abner K, Adamberg K, Vilu R: Steady state growth space study of Lactococcus lactis in D-stat cultures. Antonie Van Leeuwenhoek 2009, 96:487-96.

28. Adamberg K, Lahtvee PJ, Valgepea K, Abner K, Vilu R: Quasi steady state growth of Lactococcus lactis in glucose-limited acceleration stat (A-stat) cultures. Antonie van Leeuwenhoek 2009, 95:219-26.

29. Lowry $\mathrm{OH}$, Rosebrough NJ, Farr AL, Randall RJ: Protein measurement with the Folin phenol reagent. J Biol Chem 1951, 193:265-75.

30. Špitsmeister M, Admaberg K, Vilu R: UPLC/MS based method for quantitative determination of fatty acid composition in Gram-negative and Gram-positive bacteria. J Microbiol Methods 2010, 82:288-95.

31. Oliveira A, Nielsen J, Forster J: Modeling Lactococcus lactis using a genome-scale flux model. BMC Microbiol 2005, 5:39.

32. Rorabacher DB: Statistical treatment for rejection of deviant values: critical values of Dixon's " $Q$ " parameter and related subrange ratios at the 95\% confidence level. Analyt Chem 1991, 63:139-146.

33. Rappsilber J, Mann M, Ishihama Y: Protocol for micro-purification, enrichment, pre-fractionation and storage of peptides for proteomics using StageTips. Nat Prot 2007, 2:1896-906.

34. Köcher T, Pichler P, Schutzbier M, Stingl C, Kaul A, Teucher N, Hasenfuss G, Penninger JM, Mechtler K: High precision quantitative proteomics using iTRAQ on an LTQ Orbitrap: a new mass spectrometric method combining the benefits of all. J Prot Research 2009, 8:4743-52.

35. $\mathrm{Xu} \mathrm{H}$, Freitas MA: MassMatrix: a database search program for rapid characterization of proteins and peptides from tandem mass spectrometry data. Proteom 2009, 9:1548-55.

36. Martens L, Hermjakob H, Jones P, Adamski M, Taylor C, States D, Gevaert K, Vandekerckhove J, Apweiler R: PRIDE: the proteomics identifications database. Proteomics 2005, 5:3537-3545. 
37. Barsnes H, Vizcaíno JA, Eidhammer I, Martens L: PRIDE Converter: making proteomics data-sharing easy. Nat Biotechnol 2009, 27:598-599.

38. Ganesan B, Dobrowolski P, Weimer BC: Identification of the leucine-to-2methylbutyric acid catabolic pathway of Lactococcus lactis. Appl Environ Microbiol 2006, 72:4264-73.

39. Chambellon E, Rijnen L, Lorquet F, Gitton C, van Hylckama Vlieg JET, Wouters JA, Yvon M: The D-2-hydroxyacid dehydrogenase incorrectly annotated PanE is the sole reduction system for branched-chain 2-keto acids in Lactococcus lactis. J Bacteriol 2009, 191:873-81.

doi:10.1186/1475-2859-10-12

Cite this article as: Lahtvee et al:: Multi-omics approach to study the growth efficiency and amino acid metabolism in Lactococcus lactis at various specific growth rates. Microbial Cell Factories 2011 10:12.

\section{Submit your next manuscript to BioMed Central} and take full advantage of:

- Convenient online submission

- Thorough peer review

- No space constraints or color figure charges

- Immediate publication on acceptance

- Inclusion in PubMed, CAS, Scopus and Google Scholar

- Research which is freely available for redistribution

Submit your manuscript at www.biomedcentral.com/submit 